\title{
PLANIFICACIÓN TURÍSTICA EN EXTREMADURA. ANÁLISIS DE SUS TERRITORIOS TURÍSTICOS
}

\author{
Ana Nieto Masot* \\ Universidad de Extremadura \\ https://orcid.org/0000-0001-9301-8637 \\ Nerea Ríos Rodríguez \\ Universidad de Extremadura \\ https://orcid.org/0000-0003-0307-5609 \\ Gema Cárdenas Alonso \\ Universidad de Extremadura \\ https://orcid.org/0000-0002-4977-8599
}

\section{RESUMEN}

Desde finales del siglo XX, la aparición de nuevas tendencias y modelos de consumo del turismo ha permitido la proliferación de equipamientos turísticos en Extremadura, optándose por la explotación de los recursos patrimoniales, tanto naturales como culturales. Así, en este trabajo se analizan la oferta y demanda del sector turístico en la región extremeña, haciendo hincapié en la clasificación por Territorios Turísticos del gobierno regional. Para ello, se realiza un análisis de variables económicas, patrimoniales y sociales mediante las técnicas de Regresión Lineal Múltiple (OLS), Análisis de Componentes Principales y Sistemas de Información Geográfica (SIG). Se podrá ver qué Territorios Turísticos han implantado mejores líneas de actuación encaminadas a la recepción de visitantes, al incremento de las rentas económicas y a una preservación de la población en los espacios rurales, así como cuáles presentan deficiencias en su desarrollo turístico.

Palabras clave: Demanda turística; Oferta turística; Regresión Lineal Múltiple; Análisis de Componentes Principales; SIG.

Tourist planning in Extremadura. Analysis of its tourist territories

Fecha de recepción: 4 de mayo de 2019

Fecha de aceptación: 12 de diciembre de 2019

* Departamento de Arte y Ciencias del Territorio. Facultad de Filosofía y Letras. Campus Universitario s/n 10.071 CÁCERES (España).E-mail: ananieto@unex.es, nerearios@unex.es, gemacardenas@unex.es 


\begin{abstract}
Since the end of the last century, the development of new trends and tourism consumption models has allowed the proliferation of tourist equipment in Extremadura, exploiting the heritage resources, both natural and cultural. In this paper, supply and demand of tourist sector in Extremadura are analyzed, emphasizing the classification by Tourist Territories of the regional government. For this, economic, social and patrimonial variables are studied through the Multiple Linear Regression statistic (OLS), Principal Components Analysis (PCA)and Geographic Information Systems (GIS). It will be seen what Tourist Territories have implemented better strategies intend to reception of visitors, the increase of economic rents and the preservation of the population in rural areas, as well as which ones present deficiencies in their tourist development.
\end{abstract}

Keywords: Tourist demand; Tourist offer; Multiple Linear Regression;Principal Components Analysis; GIS.

\title{
1. INTRODUCCIÓN
}

Extremadura es una comunidad autónoma del interior de España en la que el fenómeno del turismo ha experimentado una importante expansión en las últimas décadas. Esta región cuenta con un amplio atractivo debido a su localización y condiciones territoriales y, se articula en base a dos cuencas hidrográficas, la del río Tajo en la provincia de Cáceres y la del río Guadiana en la provincia de Badajoz, y a tres grandes sistemas montañosos situados de forma paralela: el Sistema Central al norte, las Sierras Centrales Extremeñas y Sierra Morena al sur. Además, existen numerosas penillanuras repartidas a lo largo y ancho de la región y abundantes sierras de una altitud relativamente baja (Nieto, 2014). Esta configuración territorial favoreció la llegada y asentamiento de numerosos pueblos, civilizaciones y culturas a lo largo de la historia que transmitieron su legado histórico-cultural en forma de diferentes obras arquitectónicas, las cuales son explotadas, actualmente, como recursos turísticos. La existencia de un amplio patrimonio en Extremadura y su reconocimiento conllevó a la necesidad de protección y conservación del mismo, mediante la creación de un marco jurídico que amparase su defensa, contando, además, con las desventajas que presentaba la región frente al turismo "de sol y playa" por el que se apostó en los años 60. Sin embargo, la excesiva promoción de este tipo de turismo durante las siguientes décadas y el escaso control en su expansión constructiva originó masificación en determinadas zonas, deterioro de espacios naturales y una crisis del modelo. También, la aparición de nuevas tendencias y modelos de consumo del turismo como la búsqueda de otras ofertas relacionadas con el patrimonio cultural o natural, estancias menores (de fin de semana) de los urbanitas en espacios rurales y poco degradados en busca de descanso y naturaleza (Hernández et al., 2008), propiciaron la aparición y práctica de nuevos modelos turísticos a finales de los años 80 y principios de los 90, desarrollándose el sector en otras zonas de la geografía española. Por ello, teniendo en cuenta el alto valor histórico, cultural, patrimonial y natural con 
el que cuentan numerosos territorios españoles, se apostó por el desarrollo de nuevos destinos turísticos cuyas características principales son: una escasa transformación del territorio, una rica oferta gastronómica, un amplio conjunto de enclaves y parajes naturales y artesanía y folklore tradicionales (Nieto y Cárdenas, 2017).

Este cambio en la concepción del turismo español ha beneficiado notablemente al turismo de Extremadura, con un gran desarrollo a partir de los años 90 debido, sobre todo, a la implantación de nuevas políticas económicas de la Dirección General de Turismo de la Junta de Extremadura que favoreció la creación de una infraestructura hotelera, ayudada por la mejora de las vías de comunicación financiada por los Fondos Estructurales y el Fondo de Cohesión europeos o a través de iniciativas específicas, también de la UE, como INTERREG o LEADER (Vázquez y Martín, 2011; Cánoves y Villarino, 2005).

En 2006, el Comité Económico y Social Europeo (CESE), en su dictamen sobre «La contribución del turismo a la recuperación socioeconómica de las zonas en declive», establece la importancia de transformar áreas, como las rurales extremeñas, que están estancadas económicamente o que en ellas ha ido desapareciendo su modelo tradicional agrario productivo. Para ello, se impulsa el turismo rural como una actividad complementaria a las rentas agrarias de los espacios rurales afectados por la despoblación y la creciente crisis de su modelo productivo, con el fin de que puedan lograr crecimiento económico y el mantenimiento o crecimiento de su población (García y De la Calle, 2006; Cuadrado y López, 2015).

Ante lo anterior, la hipótesis de investigación es que existen Territorios Turísticos que han logrado un óptimo diseño de su estructura turística y, por ello, estén recibiendo un número considerable de turistas que puedan estar contribuyendo al desarrollo de las rentas económicas y a un mantenimiento de la población rural. Se ha determinado que el área de trabajo son los Territorios Turísticos establecidos por la Dirección General de la Junta de Extremadura por ser el ámbito espacial de actuación para el diseño de las diferentes políticas turísticas en nuestra región.Así, el objetivo de este trabajo es analizar el sector turístico en Extremadura y además, su relación con otras variables de contexto, como es el mantenimiento de su población y el PIB. Para concretar, el planteamiento es comprobar mediante Sistemas de Información Geográfica y técnicas estadísticas(modelo de Regresión Lineal Múltiple y el Análisis de Componentes Principales) si la apuesta por el sector turístico en Extremadura y el actual diseño de la oferta y demanda de sus recursos está logrando conseguir el mantenimiento de la población en determinados espacios.

En este punto, es destacable el hecho de que diversas regiones españolas han sido también sujetos de estudio en relación al sector turístico y las "comarcas" establecidas para su promoción como marca turística. De este modo, destacan los trabajos de Obiol (2002), en donde analiza las relaciones territoriales existentes en las marcas turísticas zonales de la Comunidad Valenciana y determina cómo la geografía es la gran abastecedora de los componentes básicos de una marca turística, de De Uña y Villarino (2011), para el caso de Galicia y que estudian la interacción entre territorio, identidad e imagen de los territorios turísticos gallegos, o Brunet et al. (2005), para toda España, quienes tratan sobre los Planes de Excelencia y Dinamización turística (PEDT) como instrumento favorable para el avance turístico de aquellos territorios en los que se llevan a cabo. 


\subsection{La oferta y demanda turísticas en Extremadura}

Siguiendo la definición establecida por la OMT (1998), la oferta turística es el conjunto de bienes, servicios, productos, recursos e infraestructuras que se encuentran en un determinado lugar y se estructuran de una manera disponible en el mercado para ser consumidos o usados por los turistas.

En Extremadura, según la Ley 2/2011, de 31 de enero, de desarrollo y modernización del turismo de Extremadura, la planificación de su oferta turística y su promoción ${ }^{1}$ se llevarán a cabo a través de consecutivos planes turísticos extremeños ${ }^{2}$ que fomenten el incremento y la diversificación de la oferta, segmentándola en las siguientes áreas y actividades: turismo rural y agroturismo, turismo de naturaleza, turismo cultural e históricoartístico, turismo de negocios, congresual y de incentivos, turismo gastronómico, turismo social, turismo termal, turismo educativo, turismo idiomático, turismo deportivo, así como cualquier otro tipo de turismo emergente que adquiera autonomía y sustantividad en Extremadura.

En este trabajo, la oferta turística se analizará dividiéndola en dos ámbitos o sectores, el primero en cuanto a la infraestructura, definiendo las tipologías de alojamientos y restauración existentes en la región, y el segundo respecto a los recursos patrimoniales que se ofrecen, dividiéndolos, a su vez, en patrimoniales culturales y naturales.

En cuanto los alojamientos turísticos, éstos se han diferenciado en tres bloques para poder analizarlos, distinguiendo entre alojamientos hoteleros (hoteles, hostales y pensiones), alojamientos extrahoteleros (apartamentos turísticos, albergues y campings) y alojamientos rurales (apartamentos rurales, hoteles rurales y casas rurales). Atendiendo a los establecimientos, estos se han clasificado en restaurantes, caterings y salones de banquetes.

Respecto a la oferta patrimonial cultural, se estudian los bienes protegidos por organismos internacionales, como la UNESCO, el catálogo de BIC del Ministerio de Cultura y Deporte y servicios complementarios como las bibliotecas, museos, centros de interpretación y fiestas de Interés Turístico. Por otro lado, en la oferta patrimonial natural se analizan figuras de protección internacional y nacional y, como recurso complementario, el catálogo de recursos geológicos del IGME (Instituto Geológico y Minero de España).

Por otro lado, la OMT (1998) define demanda turística como el conjunto de usuarios o turistas que, de forma individual o colectiva, están motivados por una serie de productos o servicios turísticos con el objetivo de cubrir sus necesidades. Así, se considera usuario turístico o turista a la persona que utiliza los establecimientos y bienes turísticos o recibe servicios que le ofrezcan las empresas y que los demanda y disfruta. Las exigencias de la demanda turística deberán tenerse en cuenta para la planificación y acomodación de la oferta turística de la región, según aparece en la Ley 2/2011, de 31 de enero, de desarrollo y modernización del turismo de Extremadura.

La demanda turística está compuesta por dos indicadores principales: los viajeros y las pernoctaciones, siendo los primeros "toda persona que se desplaza entre dos o más países distintos - viajero internacional-, o entre dos o más lugares dentro de su país de

1 Artículo 3 f) de la Ley 2/2011, de 31 de enero, de desarrollo y modernización del turismo de Extremadura.

2 Actualmente vigente el Plan Turístico Extremadura 2017-2020. 
residencia habitual - viajero interno-" (OMT, 1998). Con respecto a las pernoctaciones, éstas hacen referencia al número de días que permanecen los viajeros en un destino, registrándose en el lugar de alojamiento.

Por otro lado, el Instituto Nacional de Estadística (INE) establece como viajeros a aquellas personas que se desplazan a otro lugar y, al menos, pernocta una noche. De este modo, diferencia entre viajeros y excursionistas, a los que define como aquellos que se desplazan pero no se alojan en el lugar del viaje, son los también denominados como viajeros de paso.

\section{MATERIAL Y MÉTODOS}

\subsection{Diseño de bases de datos cartográficas y alfanuméricas}

En primer lugar, se construyó una base de datos cartográfica tomando como referencia la capa poligonal de municipios de Extremadura obtenida de la Base Cartográfica Nacional 1:200.000 (BCN200) del Instituto Geográfico Nacional. En esta capa se establecieron, con información tabular, los 15 Territorios Turísticos delimitados por el Observatorio de Turismo de Extremadura y la Junta de Extremadura. Dichos territorios están formados por los 4 municipios considerados urbanos (Badajoz, Cáceres, Mérida y Plasencia) y 11 "comarcas" que unifican los 384 municipios restantes de la región. Así, la capa resultante será la base cartográfica poligonal utilizada en este estudio.

Con respecto al patrimonio cultural, se georreferenciaron (buscando las coordenadas de todos los recursos culturales en el visor Iberpix) las siguientes variables:

- Bienes de Interés Cultural (BIC). Se consultó la base de datos de los bienes inmuebles inscritos en el Registro de BIC del Ministerio de Cultura y Deporte del Gobierno de España (http://www.culturaydeporte.gob.es/cultura-mecd/areascultura/patrimonio), lo que permite obtener la identificación y descripción de los bienes objeto de estudio. Además, esta información se completó con la obtenida del Observatorio extremeño de la Cultura (https://observaculturaextremadura.es). De este modo, se georreferenciaron cada uno de los BIC existentes en los municipios extremeños, sumando un total de 277, teniendo en cuenta su categoría (Conjunto Histórico, Monumentos, Sitios Históricos, Zonas Arqueológicas y Lugares de Interés Etnológico), los cuales pasarían a agregarse, posteriormente, por Territorios Turísticos.

- Lugares Patrimonio Mundial de la UNESCO. Los datos se obtuvieron a partir de la información del Ministerio de Cultura y Deporte del Gobierno de España, completando dicha información con el listado que proporciona la web de la UNESCO (http://whc.unesco.org).

- Museos, Archivos Históricos y Centros de Interpretación. Se ha trabajado la información proporcionada por el Observatorio Extremeño de la Cultura y, en el caso de los Centros de Interpretación, se han actualizado los establecidos en la web Extremadura Turismo (https://www.turismoextremadura.com). Del mismo modo que los BIC, se georreferenciaron para tener la localización de cada uno y, así, poder 
agrupar un total de 135 Museos, Archivos Históricos y Centros de Interpretación por Territorios Turísticos.

- Fiestas de Interés Turístico. Su inclusión en el análisis de la oferta turística extremeña se basa en que es un factor muy relevante en la atracción de turismo en la región, dado que la mayor parte de las fiestas se inspiran en tradiciones y costumbres de los sitios en los que se celebran. Así, se ha trabajado con una capa cartográfica disponible en el centro de descargas de la Infraestructura de Datos Espaciales de Extremadura (IDEEX) (http://www.ideextremadura.com), actualizada con la información obtenida del Observatorio Extremeño de la Cultura. En total, se llegaron a contabilizar 70 Fiestas de Interés Turístico en la región.

En cuanto al patrimonio natural se añadieron las Áreas Protegidas y los Lugares de Interés Geológico-Geomorfológico siendo los siguientes:

- Áreas Protegidas. Se obtuvieron las capas relativas a la Red de Espacios Naturales Protegidos de Extremadura (RENPEX) de la web Extremambiente de la Junta de Extremadura (http://extremambiente.juntaex.es), a las Zonas de Especial Protección para las Aves (ZEPA), los Lugares de Importancia Comunitaria (LIC) (denominados actualmente Zonas de Especial Conservación (ZEC)), las zonas RAMSAR, las Reservas de la Biosfera, las Áreas Privadas de Interés Ecológico y los Parques Nacionales, contando Extremadura con el Parque Nacional de Monfragüe. Cabe destacar que, dentro de esta clasificación, se ha añadido el Geoparque VilluercasIbores-Jara. Todos estos espacios suponen a un total de 308 áreas protegidas en la región.

- Lugares de Interés Geológico-Geomorfológico (LIG). Se estudió la información referente al patrimonio geológico mediante el documento metodológico para la elaboración del Inventario Español de Lugares de Interés Geológico (IELIG) (Vegas et al. 2014), así como el visor del mismo, del cual se obtuvo una capa de extensión .layer. Esta se utilizó para digitalizar los lugares y, así, obtener la ubicación de cada uno de ellos (147 en total).

Posteriormente, esta información cartográfica fue asignada a la capa base de los diferentes Territorios Turísticos en formato tabular para la realización de los análisis posteriores.

En segundo lugar, se creó una base de datos alfanumérica con los datos de la oferta de infraestructura turística. El número de establecimientos y las plazas existentes por establecimiento, se obtuvieron de la Dirección General de Turismo de la Junta de Extremadura en formato Excel y como elementos independientes, los cuales, a través de diversas consultas, se agruparon en tres tipos de alojamientos, estos son los hoteleros (hoteles, hostales y pensiones), extrahoteleros (apartamentos turísticos, albergues y campings) y rurales (apartamentos rurales, hoteles rurales y casas rurales). Los establecimientos de restauración se unieron en restaurantes, catering y salones de banquetes. De tal modo, se contabilizaron 1.551 establecimientos de alojamientos turísticos y 1.831 establecimientos dedicados a la restauración que se agruparon por Territorios Turísticos. 
En el caso de la demanda turística, la información originaria sobre el número de viajeros y pernoctaciones procede del INE. Su estructura es de microdatos por establecimientos y se calculan en función de los Territorios Turísticos publicados por el Observatorio de Turismo de Extremadura (2019).

En cuanto a las variables de contexto, con el fin de conocer características demográficas y socioeconómicas de la población de Extremadura, se analizan la población existente a 1 enero de 2018, el crecimiento de la población desde 2013 a 2018 y el Producto Interior Bruto (PIB), obtenido del Atlas Socioeconómico de Extremadura del año 2017, estudiando el valor medio para cada uno de los 15 Territorios Turísticos.

Finalmente, a través del SIG, la base de datos alfanumérica le fue asignada a la capa base poligonal de los Territorios Turísticos con un total de 120 variables.

\subsection{Análisis de Regresión Lineal Múltiple}

El primer análisis estadístico empleado en este trabajo es el modelo de Regresión Lineal Múltiple de tipo OLS (Ordinary Least Squares). Se trata de un modelo que permite entender la relación funcional entre la variable dependiente y las variables explicativas o predictoras y basado en el ajuste de una ecuación a un conjunto de datos mediante mínimos cuadrados (Rodríguez y Morar, 2001), siendo uno de los más empleados y usuales en todas las ciencias (Bosque y Moreno, 1994). Se calcula a partir de la siguiente ecuación:

$$
Y=\beta_{0}+\beta_{1} X_{1}+\beta_{2} X_{2}+\ldots+\beta p X p+\varepsilon
$$

Siendo $Y$ la variable dependiente (en este caso el número total de viajeros por territorio) y $X$ las variables explicativas o predictoras, las cuales afectan o intervienen en la relación con la variable dependiente, como pueden ser, en este caso, el número de pernoctaciones, las plazas por establecimiento, o incluso, cada uno de los bienes tanto culturales como naturales existentes en cada Territorio Turístico. $\beta$ se refiere a cada uno de los valores explicativos y al reflejo de la relación de cada variable explicativa de la variable dependiente; y $\varepsilon$ corresponde a los valores que no se pueden explicar por el modelo, siendo esto el error residual.

La finalidad de este análisis es determinar el grado de explicación o relación de las variables que se han estimado como explicativas (el PIB, la concentración de población, la oferta de infraestructuras y la oferta de recursos), tras medir su intensidad de asociación (Pineda et al., 2009), y que pueden afectar al número de viajeros que recibe cada Territorio Turístico, que es la variable dependiente. De este modo, las variables finalmente analizadas, por ser potencialmente útiles para el modelo de regresión, se agruparon en tres grupos, constituyendo cada uno un grupo de variables independientes que afectan a la variable dependiente:

- Sociodemográficas: Población total en 2018; Crecimiento de la Población (20132018); y PIB (2017).

- Turísticas: Pernoctaciones totales; plazas por alojamiento; plazas por establecimiento de restauración. 
- Patrimoniales: BIC; lugares Patrimonio de la Humanidad de la UNESCO; Museos; Fiestas de Interés Turístico; áreas protegidas; y Lugares de Interés GeológicoGeomorfológico.

Se analizó el coeficiente de determinación o $R^{2}$ obtenido para cada uno de los grupos, el cual mide la proporción de la varianza total de la variable dependiente respecto a su media, que es explicada por el modelo de regresión. Por otro lado, para saber el significado del valor estadístico $t$ fue necesario analizar el grado de libertad, el cual es cambiante según las variables, y el nivel de confianza. Éste último se mantuvo en un $95 \%$, de tal forma que permitiera que el parámetro a estimar se encontrara en el intervalo de confianza. Para obtener el valor exacto del estadístico $t$ se consultó la tabla de distribución $T$ de Student (Fischer y Yates, 1963), la cual muestra la distribución de probabilidad que se crea del problema de estimar la media de una población generalmente repartida cuando el tamaño de la muestra es más reducido.

\subsection{Análisis de Componentes Principales}

En segundo lugar, se realizó un Análisis de Componentes Principales (ACP) con el fin de conocer la relación existente entre las variables recopiladas y el factor de explicación de las mismas en los diferentes territorios.

El ACP es un método estadístico que tiene como objetivo el tratamiento de un conjunto de variables observadas, de tal forma que se reduzcan los datos creando un nuevo conjunto de variables ficticias denominadas componentes, las cuales son el resultado de la combinación de las variables originales (Uriel, 1995). Los componentes principales resultantes se clasifican por la cantidad de varianza original que presentan, por lo que este método es eficaz para sintetizar la dimensionalidad del conjunto de datos (Cárdenas y Nieto, 2017).

Se obtienen las comunalidades, que indican el factor de explicación de cada variable, de tal modo que, cuanto mayor grado de explicación, más se acercarán a 1 y mayor peso tendrán en el conjunto de variables; y los porcentajes de la varianza explicada, la cual ofrece un listado de los autovalores de la matriz de varianzas-covarianzas y del porcentaje de varianza que representa cada uno ellos. Los autovalores expresan la cantidad de la varianza total que es explicada por cada factor. Por último, se obtiene el factor de explicación en cada territorio respecto a los componentes principales que permite analizar qué territorios están interrelacionados con las variables según sus comunalidades.

Este método complementa al anterior por diversas razones:

1. Se establecen relaciones entre las variables sin optar por una como variable dependiente.

2. Se obtienen grados de puntuación en los diferentes Territorios Turísticos respecto a los componentes principales, definidos por la interrelación de variables causales, por lo que se podrán localizar comportamientos homogéneos en diferentes espacios. 


\section{RESULTADOS}

\subsection{Caracterización de los Territorios Turísticos de Extremadura}

En la Figura 1 se representa a Extremadura según los 15 Territorios Turísticos en los que se divide, formados, como se ha mencionado en epígrafes anteriores, por los 4 núcleos urbanos y 11 territorios que aúnan a los 384 municipios restantes.

\section{Figura 1 \\ TERRITORIOS TURÍSTICOS DE EXTREMADURA}

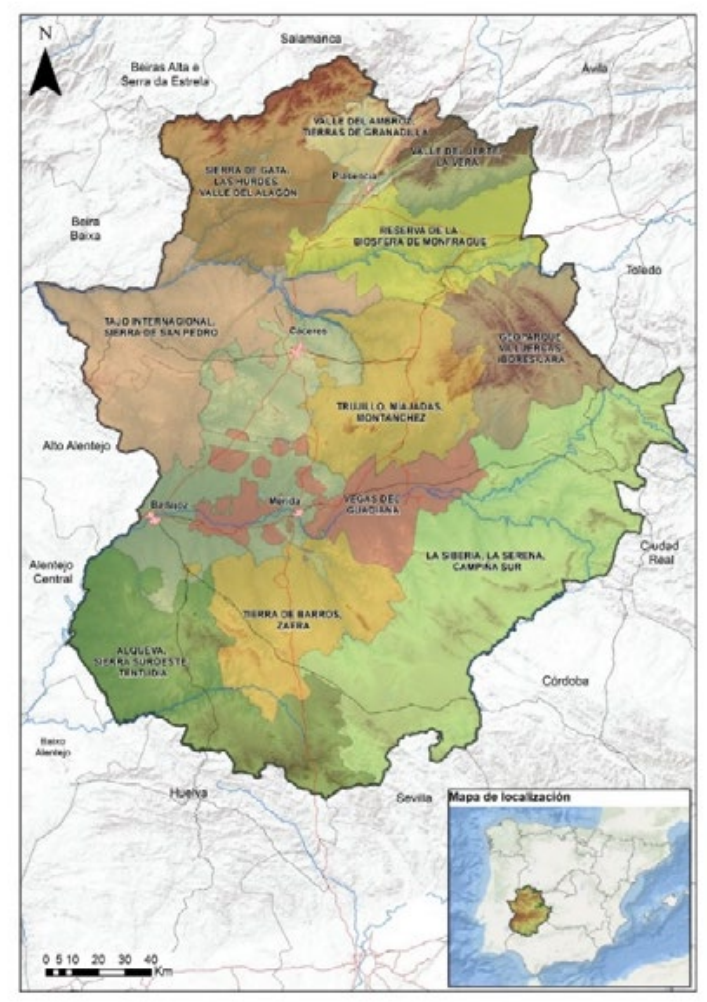

Fuente: Elaboración propia.

Como se puede apreciar en la Tabla 1, el número medio de municipios por territorio es de 25, destacando, con más de 40, los territorios de La Siberia-La Serena-Campiña Sur, Sierra de Gata-Las Hurdes-Valle del Alagón y Trujillo-Miajadas-Montánchez, y de manera opuesta, con el menor número de municipios, los territorios de Geoparque VilluercasIbores-Jara (19), Valle del Ambroz-Tierras de Granadilla (23) y Tajo Internacional-Sierra de San Pedro (23). En cuanto a las características demográficas, contando con una media 
regional de 71.524 habitantes y con que los cuatro núcleos urbanos oscilan entre los 40.000 habitantes (Plasencia) y los 150.000 habitantes (150.000), se identifican dos tendencias:

- Territorios Turísticos con mayor volumen y densidad de población y menor descenso de la población como consecuencia de la existencia de importantes cabeceras comarcales. Destacan los territorios de Vegas Altas del Guadiana y Tierra de Barros-Zafra, áreas dedicadas al regadío y una agricultura productiva de viñedo y olivar, a lo que se suma una adecuada accesibilidad territorial por tener próximas las dos principales vías de comunicación (autovías A-5 y Ruta de la Plata).

- Territorios Turísticos con una población menor de 50.000 habitantes y, en algunos casos, de 25.000, localizados en áreas de montaña y en los límites exteriores de las dos provincias de la región, donde existe la mayor pérdida de población.

Tabla 1

\section{INDICADORES TERRITORIALES Y DEMOGRÁFICOS DE EXTREMADURA}

\begin{tabular}{|c|c|c|c|c|c|c|}
\hline $\begin{array}{c}\text { Territorios } \\
\text { Turísticos } \\
\text { de Extremadura }\end{array}$ & Provincia & Municipios & $\begin{array}{c}\text { Población } \\
2018\end{array}$ & $\begin{array}{l}\text { Crecimiento } \\
\text { Población } \\
\text { (2013-2018) }\end{array}$ & $\begin{array}{c}\text { Superficie } \\
\left(\mathbf{K m}^{2}\right)\end{array}$ & $\begin{array}{c}\text { Densidad } \\
\text { de } \\
\text { Población } \\
\left(\mathbf{K m}^{2}\right)\end{array}$ \\
\hline Badajoz (Ciudad) & Badajoz & 1 & 150.530 & $-0,060$ & $1.470,43$ & 102,37 \\
\hline Cáceres (Ciudad) & Cáceres & 1 & 96.068 & 0,149 & $1.750,33$ & 54,89 \\
\hline Mérida (Ciudad) & Badajoz & 1 & 59.352 & 0,513 & 865,61 & 68,57 \\
\hline Plasencia (Ciudad) & Cáceres & 1 & 40.141 & $-2,207$ & 217,94 & 184,18 \\
\hline $\begin{array}{c}\text { Alqueva-Sierra } \\
\text { Suroeste-Tentudía }\end{array}$ & Badajoz & 30 & 82.239 & $-3,765$ & $4.459,19$ & 18,44 \\
\hline $\begin{array}{l}\text { Tierra de Barros- } \\
\text { Zafra }\end{array}$ & Badajoz & 34 & 129.111 & $-3,320$ & $2.982,51$ & 43,29 \\
\hline $\begin{array}{c}\text { La Siberia- La } \\
\text { Serena- Campiña Sur }\end{array}$ & Badajoz & 58 & 93.362 & $-6,011$ & $8.426,57$ & 11,08 \\
\hline Vegas del Guadiana & Badajoz & 38 & 148.439 & $-2,152$ & $2.473,19$ & 60,02 \\
\hline $\begin{array}{c}\text { Geoparque } \\
\text { Villuercas-Ibores- } \\
\text { Jara }\end{array}$ & Cáceres & 19 & 12.885 & $-7,548$ & $2.546,53$ & 5,06 \\
\hline $\begin{array}{l}\text { Reserva de la } \\
\text { Biosfera de } \\
\text { Monfragüe }\end{array}$ & Cáceres & 30 & 46.893 & $-3,359$ & $2.714,71$ & 17,27 \\
\hline $\begin{array}{l}\text { Sierra de Gata- Las } \\
\text { Hurdes-Valle del } \\
\text { Alagón }\end{array}$ & Cáceres & 53 & 63.963 & $-4,882$ & $3.548,29$ & 18,03 \\
\hline $\begin{array}{l}\text { Tajo Internacional- } \\
\text { Sierra de San Pedro }\end{array}$ & Cáceres & 27 & 49.676 & $-6,473$ & $4.723,8$ & 10,52 \\
\hline $\begin{array}{l}\text { Trujillo-Miajadas- } \\
\text { Montánchez }\end{array}$ & Cáceres & 42 & 48.610 & $-4,207$ & $3.318,03$ & 14,65 \\
\hline
\end{tabular}




\begin{tabular}{|c|c|c|c|c|c|c|}
\hline $\begin{array}{c}\text { Territorios } \\
\text { Turísticos } \\
\text { de Extremadura }\end{array}$ & Provincia & Municipios & $\begin{array}{c}\text { Población } \\
\mathbf{2 0 1 8}\end{array}$ & $\begin{array}{c}\text { Crecimiento } \\
\text { Población } \\
\mathbf{( 2 0 1 3 - 2 0 1 8})\end{array}$ & $\begin{array}{c}\text { Superficie } \\
\left.\mathbf{( K m}^{\mathbf{2}}\right)\end{array}$ & $\begin{array}{c}\text { Densidad } \\
\mathbf{d e} \\
\text { Población } \\
\left(\mathbf{K m}^{\mathbf{2}}\right)\end{array}$ \\
\hline $\begin{array}{c}\text { Valle del Ambroz- } \\
\text { Tierras de Granadilla }\end{array}$ & Cáceres & 23 & 16.610 & $-3,688$ & 942,18 & 17,63 \\
\hline $\begin{array}{c}\text { Valle del Jerte-La } \\
\text { Vera }\end{array}$ & Cáceres & 30 & 34.984 & $-4,193$ & $1.257,37$ & 27,82 \\
\hline Total & - & 388 & 1.072 .863 & $-3,413$ & $41.696,68$ & 25,73 \\
\hline
\end{tabular}

Fuente: Elaboración propia a partir de datos del INE.

\section{Figura 2}

\section{BIENES DE INTERÉS CULTURAL Y PATRIMONIO UNESCO}
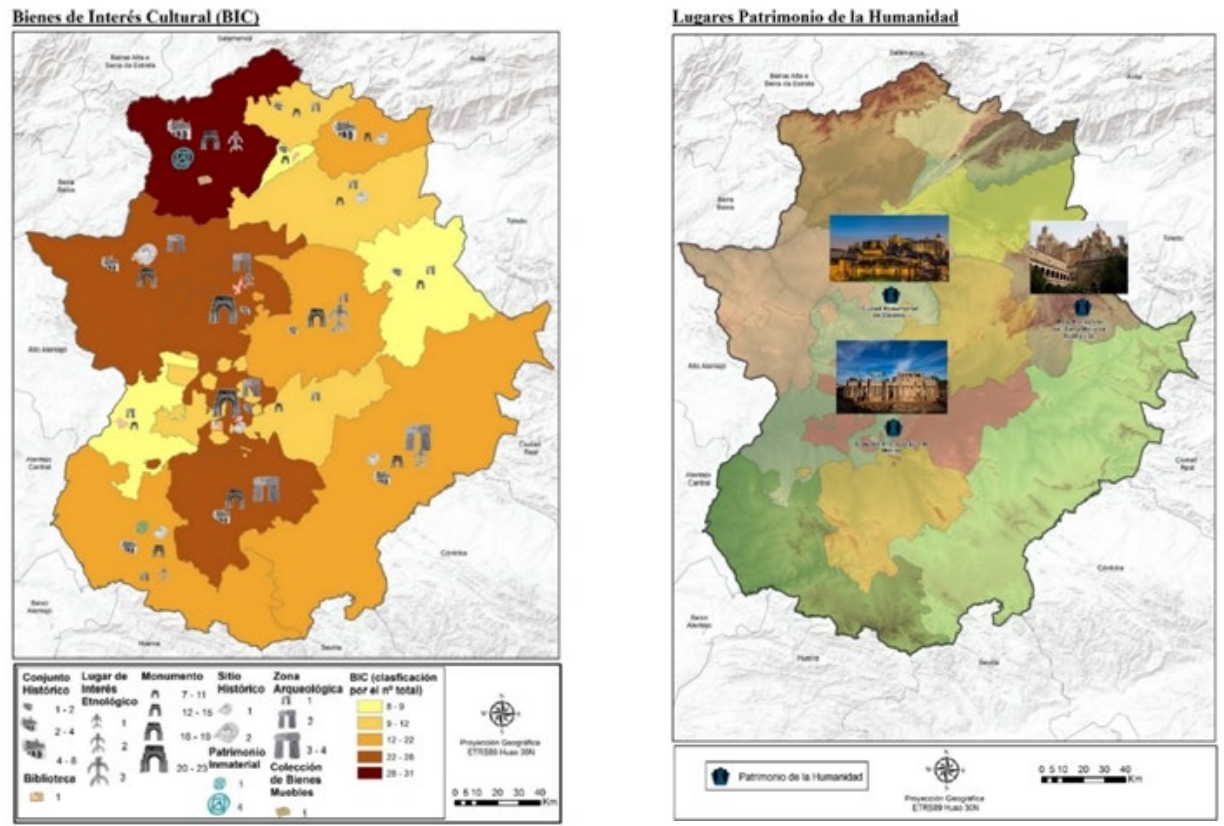

Fuente: Elaboración propia.

En relación a la oferta turística, analizada en este trabajo a partir del patrimonio cultural y natural y la infraestructura turística (alojamientos y restauración), cabe destacar el hecho de que Extremadura, en su conjunto, presenta un interesante pasado histórico fruto de las civilizaciones y asientos de éstas en diversos puntos de la región, y, consecuentemente, un valioso patrimonio histórico, artístico, arqueológico y arquitectónico. Así, hay un total de 277 BIC (Figura 2), con 35 Conjuntos Históricos, 199 Monumentos (109 de carácter religioso y 95 civil y militar), 7 Sitios Históricos, 20 Zonas Arqueológicas, 9 Lugares de Interés Etnológico, 2 bienes muebles y 5 BIC de carácter etnográfico (inmateriales). Destacan, según el número 
de BIC, los territorios de Sierra de Gata-Las Hurdes- Valle del Alagón (31), Mérida (28) y Tierra de Barros-Zafra (27) y, en el extremo opuesto, Geoparque Villuercas-Ibores-Jara (9), Badajoz (8) y Plasencia (8).Por otro lado, hay 3 lugares declarados Patrimonio Mundial por la UNESCO (Figura 2), como son la Ciudad Vieja de Cáceres, el Conjunto Arqueológico de Mérida y el Real Monasterio de Santa María de Guadalupe, estando este último en uno de los territorios más ruralizados (Geoparque Villuercas-Ibores-Jara).

\section{Figura 3 \\ MUSEOS, ARCHIVOS HISTÓRICOS Y CENTROS DE INTERPRETACIÓN Y FIESTAS DE INTERÉS TURÍSTICO}
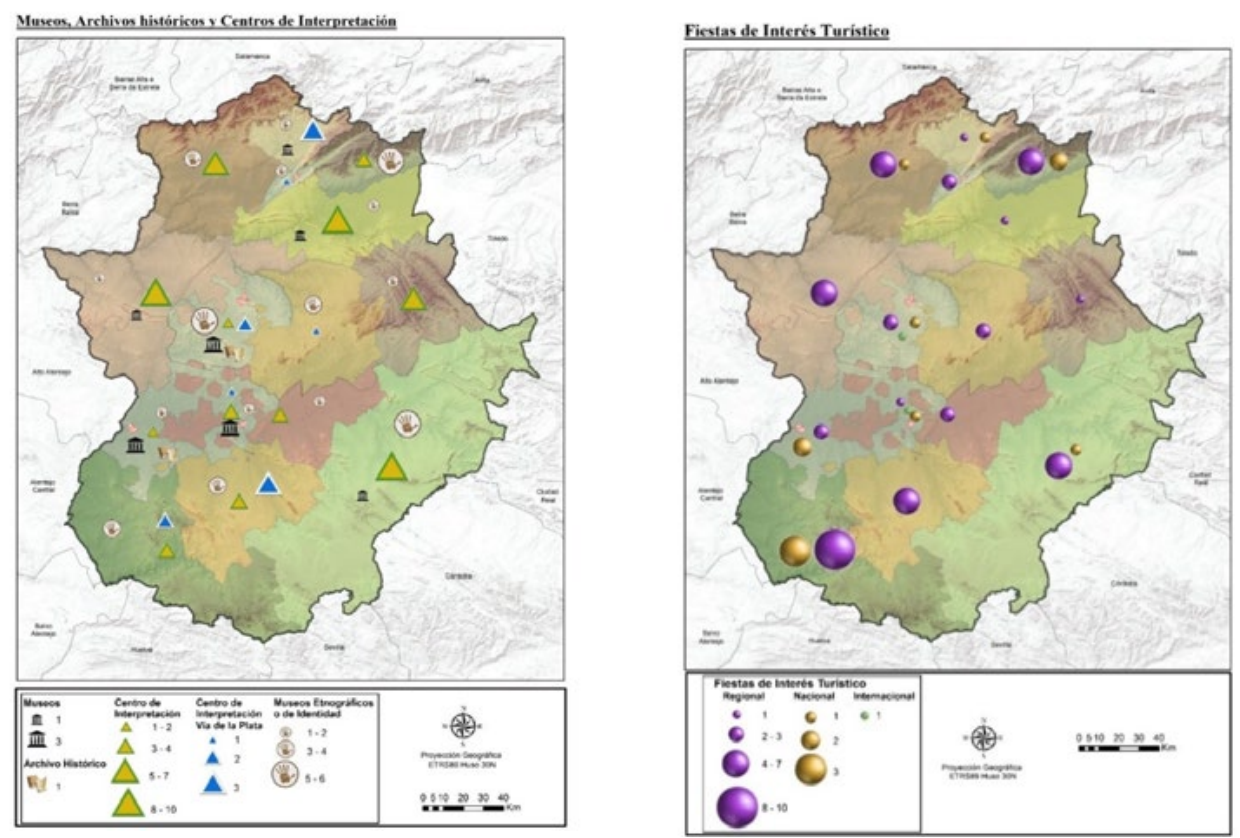

Fuente: Elaboración propia.

En lo que respecta a los recursos etnográficos, artísticos, históricos y culturales, Extremadura presenta un total de 135 con Museos (13), los Archivos Históricos (2), los Centros de Interpretación (62), los Centros de Interpretación de la Vía de la Plata (13) y los Museos Etnográficos o de Identidad (46) (Figura 3), destacando el territorio de La Siberia-La Serena-Campiña Sur con un total de 16, siendo reseñable el número de centros de interpretación de carácter público. Es necesario mencionar las Fiestas de Interés Cultural de Extremadura (Figura 3), las cuales se clasifican en función de su carácter: Internacional (2), Nacional (12) y Regional (56). Alqueva- Sierra Suroeste-Tentudía predomina sobre los demás territorios con un total de 13 fiestas de distinto carácter, como por ejemplo, la Semana Santa de Jerez de los Caballeros o Las Diablas de Valverde de Leganés. En caso 
contrario, con solo una Fiesta De Interés Turístico, se encuentran el Geoparque VilluercasIbores-Jara y la Reserva de la Biosfera de Monfragüe. Estas fiestas se caracterizan por representar momentos especiales de la vida de su población, por reproducir manifestaciones relacionadas con la religión, ritos, luchas... de tal modo que permita conocer mejor las costumbres de los lugares. Entre las más destacadas se encuentran la Semana Santa de Cáceres y de Mérida, ambas de carácter internacional, y otras muy conocidas de carácter nacional como son El Cerezo en Flor en el Valle del Jerte o el Carnaval de Badajoz.

\section{Figura 4 \\ ÁREAS PROTEGIDAS Y LUGAR DE INTERÉS GEOLÓGICO}
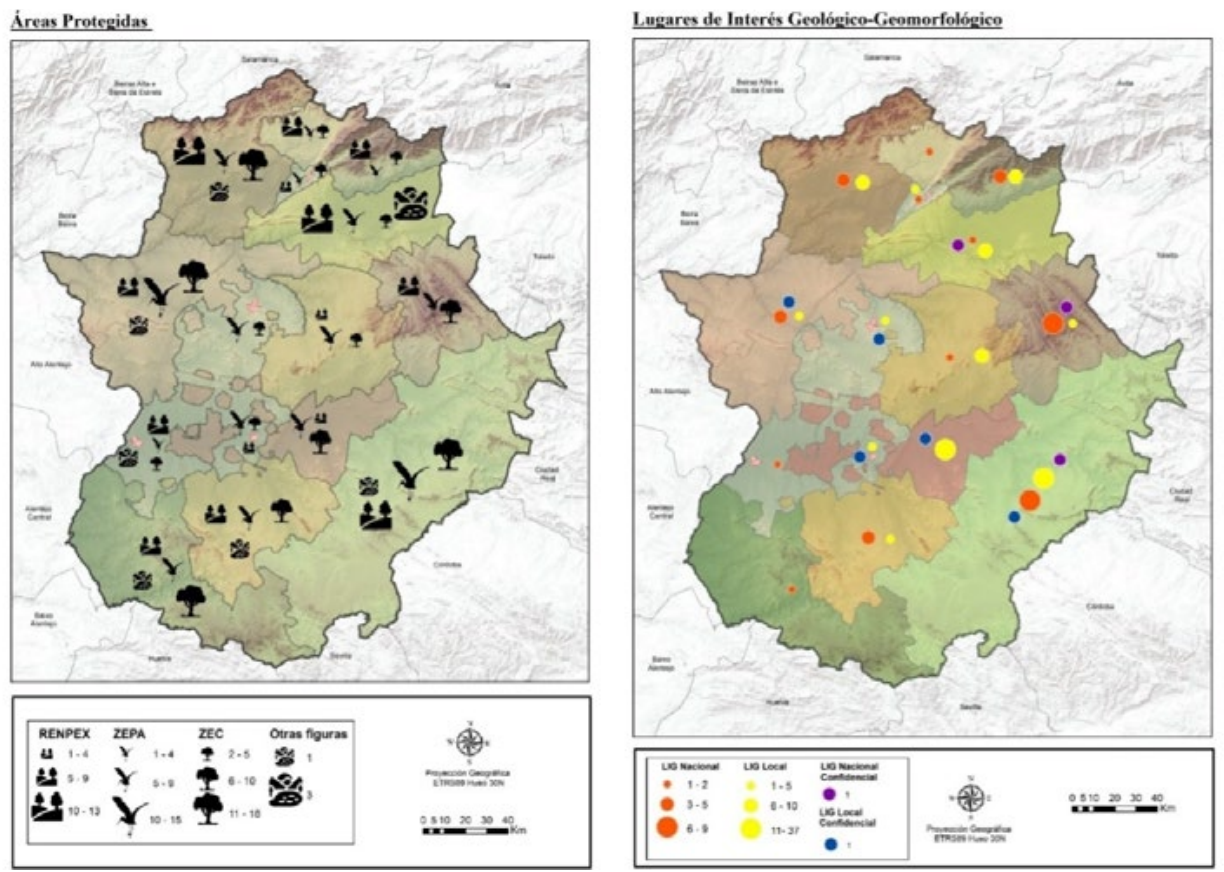

Fuente: Elaboración propia.

Respecto al patrimonio natural con el que cuenta la región, hay un total de 308 áreas protegidas. Es necesario mencionar que una misma área puede ocupar zonas pertenecientes a varios Territorios Turísticos, como es el caso de la Sierra de San Pedro, que pertenece a Tajo Internacional- Sierra de San Pedro y a Cáceres. De este modo, hay 90 áreas pertenecientes a la Red de Espacios Naturales Protegidos de Extremadura (RENPEX), 93 Zonas de Especial Conservación de Aves (ZEPA), 116 Zonas de Especial Conservación (ZEC) y otras 9 figuras como las zonas RAMSAR, las Reservas de la Biosfera y las Áreas Privadas de Interés Ecológico, sin olvidar los parques naturales de Cornalvo y Tajo Internacional, el Parque Nacional de Monfragüe y las reservas de la Biosfera de Monfragüe y Tajo-Tejo Internacional (Figura 4). Extremadura posee un elevado porcentaje de áreas protegidas, 
en concreto, un 30,6\% según la Junta de Extremadura, debido, en muchos casos, a la gran extensión de las mismas. Así, por Territorio Turístico, sobresalen los casos de La SiberiaLa Serena-Campiña Sur (43), seguido de Tajo Internacional-Sierra de San Pedro y Sierra de Gata-Las Hurdes-Valle del Alagón, ambas con un total de 35 áreas. En el extremo opuesto, se encuentran los territorios próximos a los núcleos urbanos, como es el caso de Plasencia con tan solo 4 áreas.

Los LIG (Figura 4), con un total de 147, siguen un patrón similar al de las áreas protegidas, encontrando en La Siberia-La Serena-Campiña Sur 47 LIG. Por el contrario, el territorio de Alqueva-Sierra Suroeste-Tentudía tan solo presenta un LIG conocido como Complejo Lagunar de la Albuera.

En lo que respecta a la infraestructura turística de la región, destacan las plazas de alojamientos hoteleros (Figura 5) sobre el resto de tipologías, sobre todo en las ciudades de Badajoz, Mérida y Cáceres. El territorio Tierra de Barros-Zafra presenta 2.203 plazas hoteleras, teniendo presente que cuenta con las ciudades de Almendralejo, Zafra y Villafranca de los Barros, las cuales superan los 10.000 habitantes. Respecto al tamaño de los alojamientos hoteleros, los que ofertan un mayor número de plazas son los localizados en los 4 núcleos urbanos, con una oferta media de más de 70 plazas por establecimiento. En el lado opuesto, con pocas plazas hoteleras, hay territorios en la provincia de Cáceres, como el Valle del Jerte-La Vera, Geoparque Villuercas-Ibores-Jara y Tajo InternacionalSierra de San Pedro, y en la provincia pacense con Alqueva-Sierra Suroeste-Tentudía y La Siberia-la Serena- Campiña Sur, con una media de menos de 30 plazas hoteleras, esto es debido al predominio de pequeños hostales.

\section{Figura 5 \\ N DE ESTABLECIMIENTOS Y PLAZAS OFERTADAS POR TIPO DE ALOJAMIENTO TURÍSTICO}
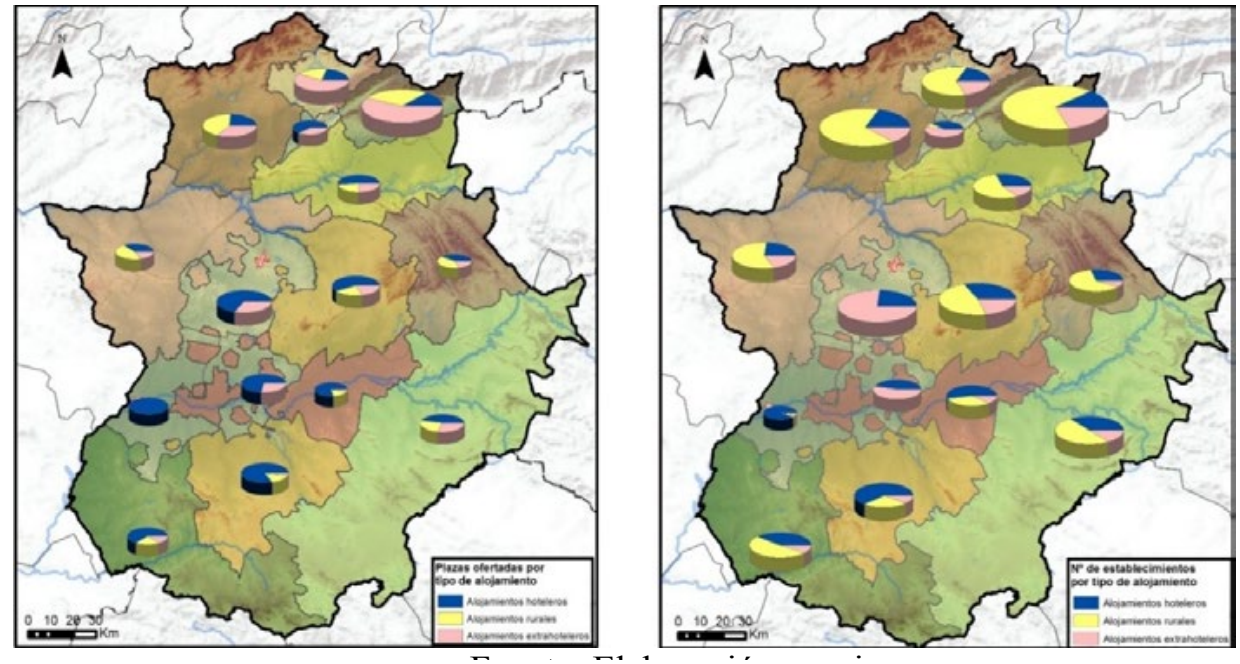

Fuente: Elaboración propia. 
En cuanto a los alojamientos rurales, el mayor número de plazas se encuentra en territorios del norte de Extremadura, destacando principalmente Valle del Jerte-La Vera, con 2.567, y Sierra de Gata-Las Hurdes-Valle del Alagón, con 1.410. Por el contrario, están las ciudades de la región, las cuales no superan las 20 plazas. El número de alojamientos va unido a los datos de plazas, de modo que son los anteriores territorios los que también mayor número de establecimientos rurales tienen, con 187 y 137, respectivamente.

El mayor número de plazas en alojamientos extrahoteleros se distribuye por el norte de la región, destacando por encima de los demás territorios el Valle del Jerte - La Vera (4.396), Valle del Ambroz, Tierras de Granadilla (2.095) y Sierra de Gata, Las Hurdes, Valle de Alagón (1.255). Todos ellos por el elevado número de plazas ofertadas de camping. Es necesario destacar Cáceres como la ciudad con más plazas en alojamientos extrahoteleros, con 1.191 plazas, las cuales, en gran medida relacionadas con apartamentos turísticos.

\section{Figura 6}

\section{N DE ESTABLECIMIENTOS Y PLAZAS OFERTADAS POR TIPO DE RESTAURACIÓN}
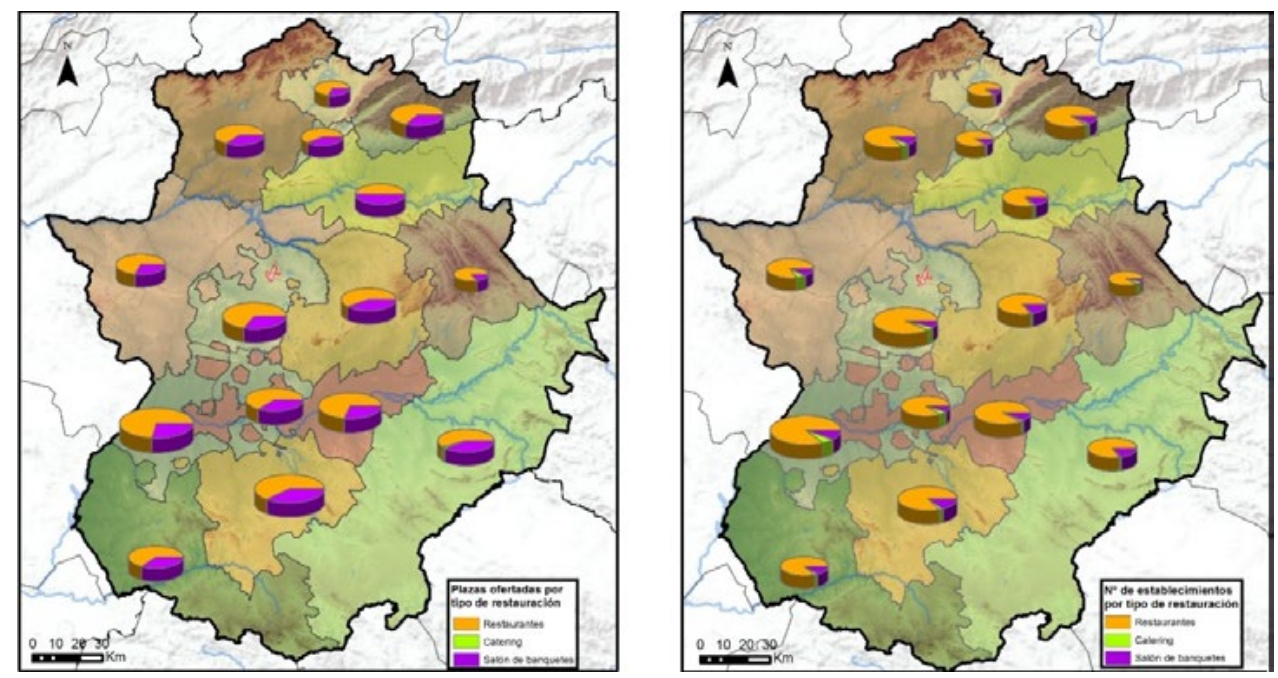

Fuente: Elaboración propia.

Por último, en cuanto a la demanda turística, en el año 2018 Extremadura recibió 1.866 .168 viajeros, de los cuales el $83,1 \%$ fue de procedencia nacional y el 16,8\% extranjera (Observatorio de Turismo de Extremadura, 2019), con una distribución homogénea a lo largo del año con repuntes en Semana Santa y en los meses estivales. La mayor parte de los viajeros (33\%) llega a Extremadura en verano, sobre todo en el mes de agosto, pero se reparte, también, de manera homogénea, en primavera y otoño, con el $27 \%$ y $23 \%$, respectivamente (el 17\% restante en invierno), con un tipo de turismo de carácter más 
rural y paisano (Pérez y García, 2005; Pérez, Sánchez-Oro y García, 2010), gastronómico $\mathrm{y}$ cultural y en fines de semana.

En cuanto a las pernoctaciones, en el año 2018 se produjeron 3.438.641, de las cuales 2.930.766 son nacionales y 507.905 de extranjeros. Estas pernoctaciones siguen el mismo patrón de distribución que el de los viajeros, con un 32\% durante los meses de verano, un $26 \%$ en primavera, un $22 \%$ en otoño y un $20 \%$ en invierno, con una estancia media de 1,84 días relativa a las noches de los fines de semana (viernes y sábado), siendo esta muy inferior a la media nacional (3,23 días), debido, como se ha mencionado anteriormente, a la práctica de un turismo de fin de semana o de puentes festivos.

Por Territorio Turístico, Cáceres y Mérida son los que más viajeros atraen, con un $18,3 \%$ y $15,3 \%$ respectivamente, siendo dos de los tres enclaves incluidos en la lista de Lugares Patrimonio de la Humanidad por la UNESCO. A los dos primeros les sigue Badajoz, con un 11,3\%; el Valle del Jerte y la Vera, con un 7,91\% y Tierra de BarrosZafra, con un 7,66\%. Reseñar cómo el tercer lugar Patrimonio de la Humanidad, el Real Monasterio de Santa María de Guadalupe, ubicado en el municipio de Guadalupe (en el Territorio Turístico Geoparque Villuercas-Ibores-Jara), y también con la declaración de Geoparque, solo cuenta con un 1,9\%. Es decir, todavía no ha sido capaz de convertirse en un gran foco de atracción turística, aunque tenga catalogados esos dos importantes recursos, dado que existen otras variables que influyen en el auge del sector turístico como es la oferta de infraestructuras (muy relacionada con el volumen de población de los núcleos rurales), la accesibilidad a los territorios o la difusión de los mismos, entre otras causas por determinar. Junto a este último territorio destacan, con el menor número de viajeros, La Siberia- La Serena-Campiña Sur, con un 2,78\%, Tajo Internacional-Sierra de San Pedro, con un 2,28\% y la Reserva de la Biosfera de Monfragüe (3,81\%), incluso teniendo el Parque Nacional de Monfragüe.Se trata de territorios que, o bien no pueden competir con otros destinos que tienen mayores recursos turísticos, o que, aun poseyendo ricos recursos naturales y protegidos, no son capaces de desarrollar su sector turístico y atraer viajeros debido, sobre todo, al marcado carácter rural que presentan.

Con respecto a las pernoctaciones, estas siguen una pauta similar, con los valores más elevados en Cáceres y Mérida (16,13\% y 15,39\%), seguidos de zonas del norte de la región características por su naturaleza como son Valle del Jerte-La Vera $(10,81 \%)$. Después, Badajoz (9,98\%), Tierra de Barros-Zafra (9,11\%), Valle del Ambroz-Tierras de Granadilla (8,44\%), Trujillo- Miajadas-Montánchez $(5,47 \%)$ y Plasencia $(5,08 \%)$. Por oposición, los valores inferiores se vuelven a localizar en La Siberia-La Serena-Campiña Sur $(2,77 \%)$, Tajo Internacional-Sierra de San Pedro $(2,18 \%)$ y Geoparque VilluercasIbores-Jara $(1,74 \%)$. Las pernoctaciones son superiores respecto a los viajeros en los territorios del norte de Cáceres, dado que en ellos se practica un turismo rural-natural en épocas estivales durante varios días de carácter familiar que se aloja en casas rurales, apartamentos rurales o campings.

En las figuras 7 y 8 se muestra reflejada la distribución, de viajeros y pernoctaciones, por tipo de alojamiento (hotelero, extrahotelero y rural). Así, existe un mayor número de viajeros que se hospeda en alojamientos hoteleros, sobre todo en Badajoz, Cáceres y Mérida, superando los 135.000 viajeros en los tres casos. Los viajeros que prefieren los alojamientos rurales se hospedan en el norte de la región, en concreto, en el Valle del 
Jerte-La Vera, Valle del Ambroz-Tierras de Granadilla y Sierra de Gata-Las Hurdes-Valle del Alagón con más de 30.000 viajeros en cada territorio. Por su parte, los viajeros albergados en alojamientos extrahoteleros no siguen un patrón concreto, dado que los destinos elegidos se enmarcan tanto en ciudades, como Cáceres, como en territorios del norte (Valle del Jerte- La Vera). Por tanto, se podría afirmar que existe una dualidad territorial en la demanda de viajeros relacionada con el tipo de alojamiento que escogen, por un lado, las zonas de mayor volumen poblacional acogen más viajeros en establecimientos hoteleros y, por otro lado, los núcleos más ruralizados en los alojamientos rurales y extrahoteleros.

Figura 7

\section{NÚMERO DE VIAJEROS POR ALOJAMIENTO TURÍSTICO}

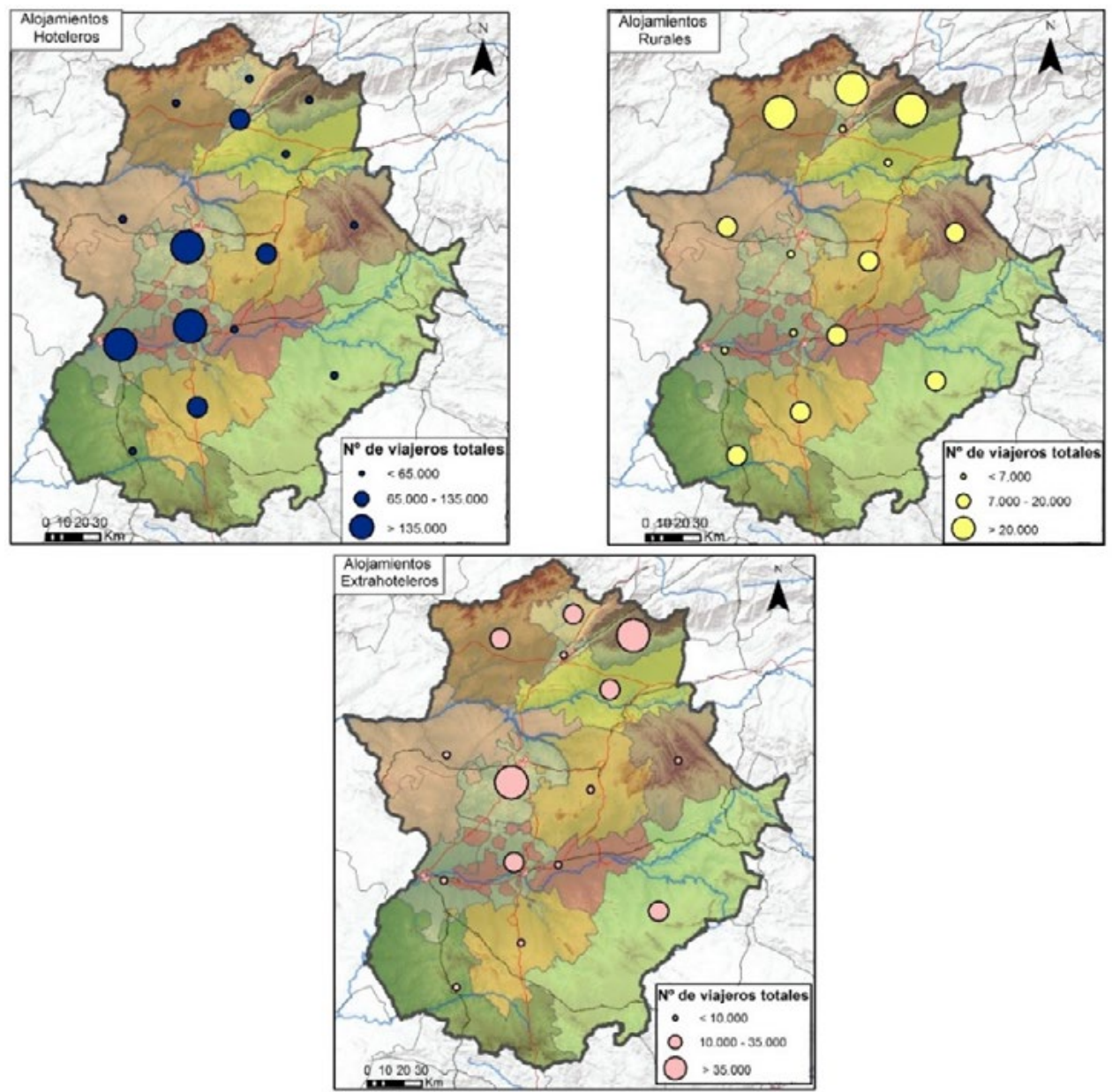

Fuente: Elaboración propia. 


\section{Figura 8 \\ NÚMERO DE PERNOCTACIONES POR ALOJAMIENTO TURÍSTICO}

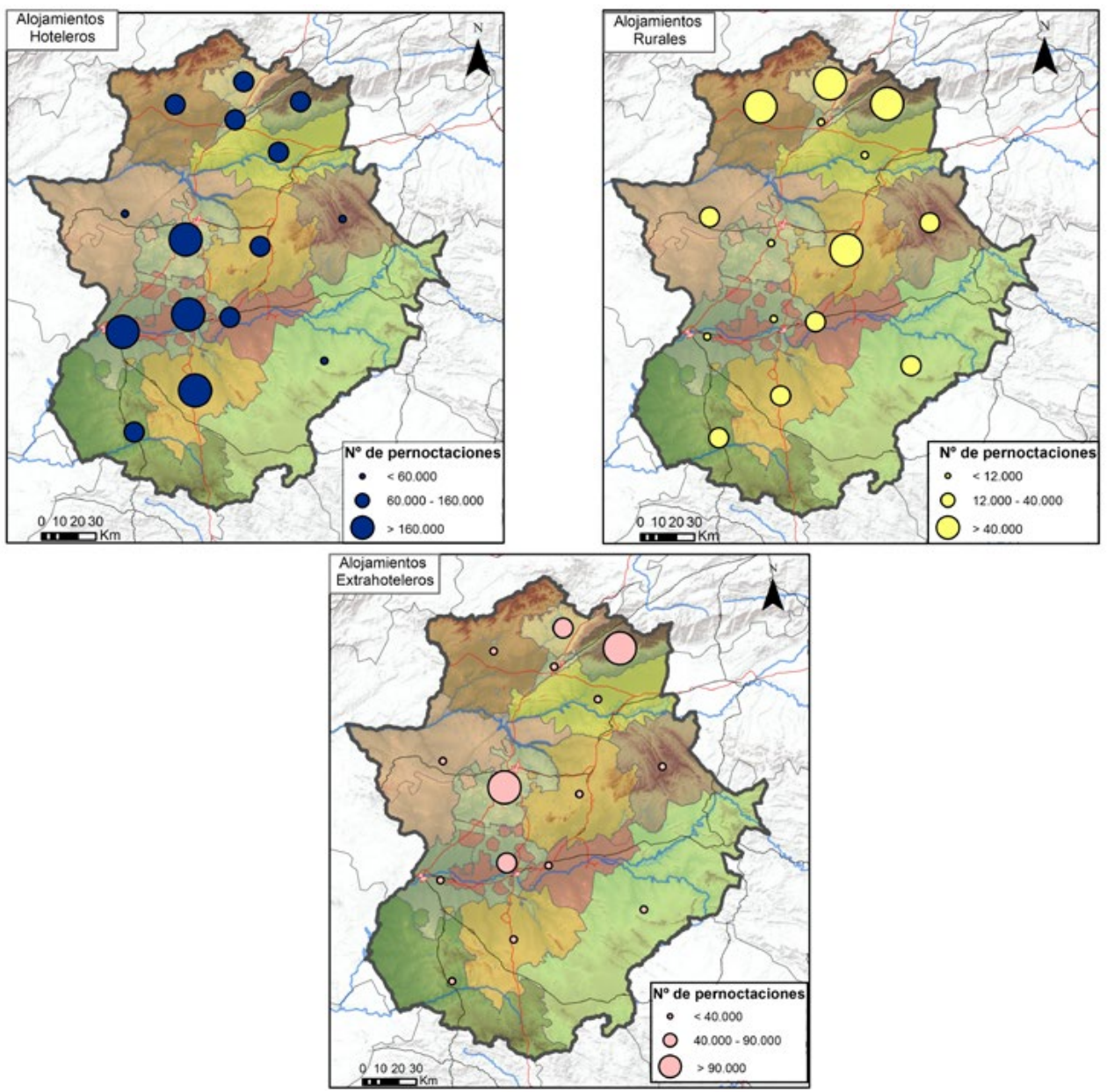

Fuente: Elaboración propia.

\subsection{Análisis de Regresión Múltiple}

Teniendo en cuenta los datos analizados previamente, se procedió a relacionar o vincular las distintas variables estudiadas utilizando como modelo estadístico la Regresión Lineal Múltiple (OLS) con el fin de entender la relación funcional entre la variable dependiente, es decir, el número total de viajeros por Territorio Turístico, y variables explicativas o independientes, las cuales se agruparon según su ámbito: sociodemográficas (población total en 2018, crecimiento poblacional de 2013 a 2018 y el PIB), turísticas (pernoctaciones 
totales, plazas por alojamientos, plazas por restauración) y patrimoniales (BIC, lugares patrimonio de la UNESCO, museos, fiestas, áreas protegidas y LIG). Se pretende determinar qué variables están correlacionadas con un mayor o menor número de viajeros en los diferentes territorios.

En primer lugar, se calculó un modelo de regresión entre el número de viajeros y las variables sociodemográficas, obteniéndose como coeficiente de determinación o $R^{2}$ un valor de 0,719 , lo que indica una estrecha relación (ya que este es próximo a 1) entre las variables explicativas o predictoras, como son la población total en 2018, el crecimiento poblacional de 2013 a 2018 y el PIB, y la variable dependiente. Estudiando el estadístico $t$, con un valor absoluto de 2,35 (para un valor de libertad de 3 y nivel de confianza del $95 \%$ ), se determina que la variable explicativa más relevante es la relativa al crecimiento de la población (Figura 9), ya que esta posee un valor de 4,90, en contraste de la población en $2018(0,9)$ y el PIB $(-0,4)$, que no son determinantes. El PIB presenta un sentido negativo, lo que se traduce en que un alto PIB en determinados territorios no supone recibir mayor número de viajeros (existen territorios, en la provincia de Cáceres, que están muy ruralizados y no presentan gran dinamismo económico pero que, por localizarse en ellos las centrales hidroeléctricas del embalse de Alcántara, en el Territorio de Tajo Internacional, o la nuclear en Almaraz, en la Reserva de la Biosfera de Monfragüe, incrementan su PIB municipal).Se puede determinar, por tanto, que aquellos territorios que han recibido mayor número de viajeros son los que han aumentado la población o presentan un menor descenso en el último quinquenio, resultado que fortalece al que ya se observaba con el análisis descriptivo previo.

\section{Figura 9 \\ CURVA DE REGRESIÓN AJUSTADA DEL CRECIMIENTO DE LA POBLACIÓN}

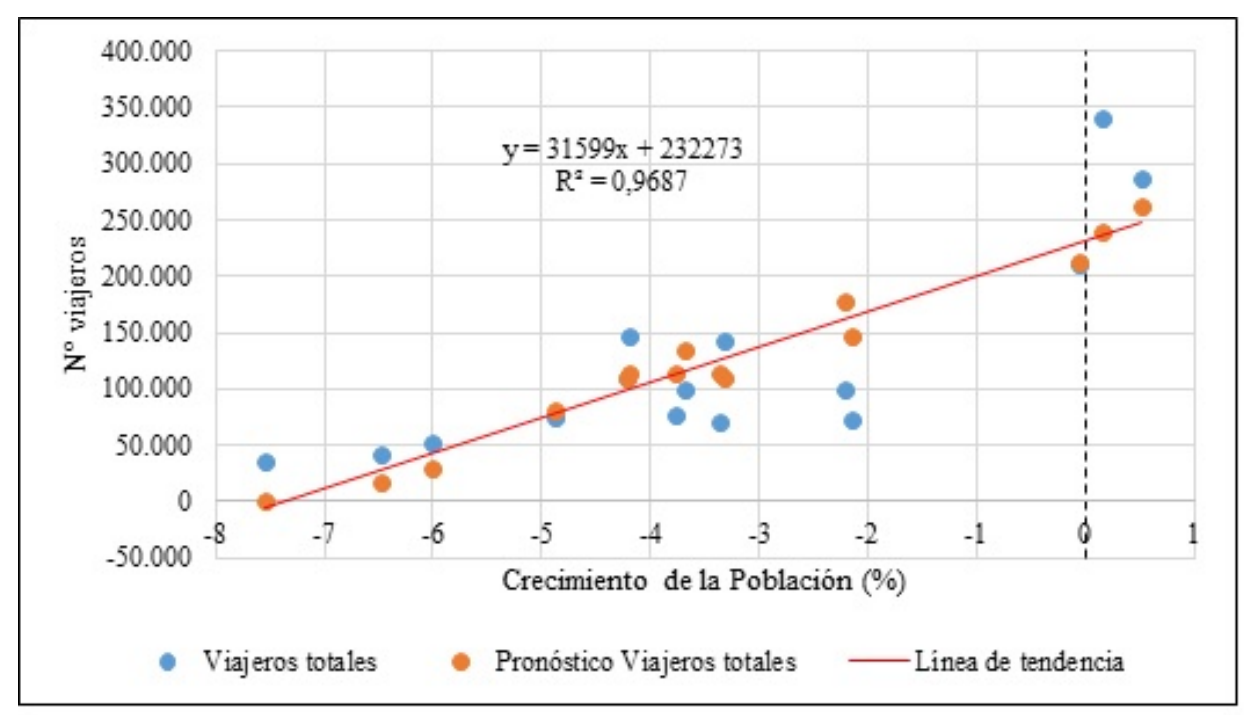


En segundo lugar, se relacionó el número de viajeros con la tipología de infraestructuras turísticas, por lo que se procedió a analizar individualmente la oferta de plazas de cada tipo de alojamiento. Como resultado del modelo de regresión lineal múltiple se obtiene un coeficiente de determinación o $R^{2}$ de 0,861 , debiendo alcanzar un valor superior al 2,35 del estadístico $t$ para un nivel de confianza del $95 \%$, ya que su grado de libertad es 3 . De tal modo, las plazas de alojamientos hoteleros (Figura 10) tienen mayor relación y con tendencia positiva $(5,2)$, por lo que un mayor número de plazas hoteleras ocasiona mayor número de viajeros. La línea de tendencia de las plazas de los alojamiento extrahoteleros (Figura 10) es también positiva pero con un valor óptimo menor $(4,08)$. Por el contrario, la relación de las plazas de alojamientos rurales (Figura 10) presenta un tendencia negativa $(-2,95)$. Así, se puede establecer que una mayor oferta de plazas hoteleras condiciona a que haya una mayor presencia de viajeros, mientras que los alojamientos rurales y los extrahoteleros no condicionan a que reciban un elevado número de viajeros y pernoctaciones.

\section{Figura 10}

CURVAS DE REGRESIÓN AJUSTADA DE PLAZAS DE ALOJAMIENTOS HOTELEROS, EXTRAHOTELEROS Y RURALES

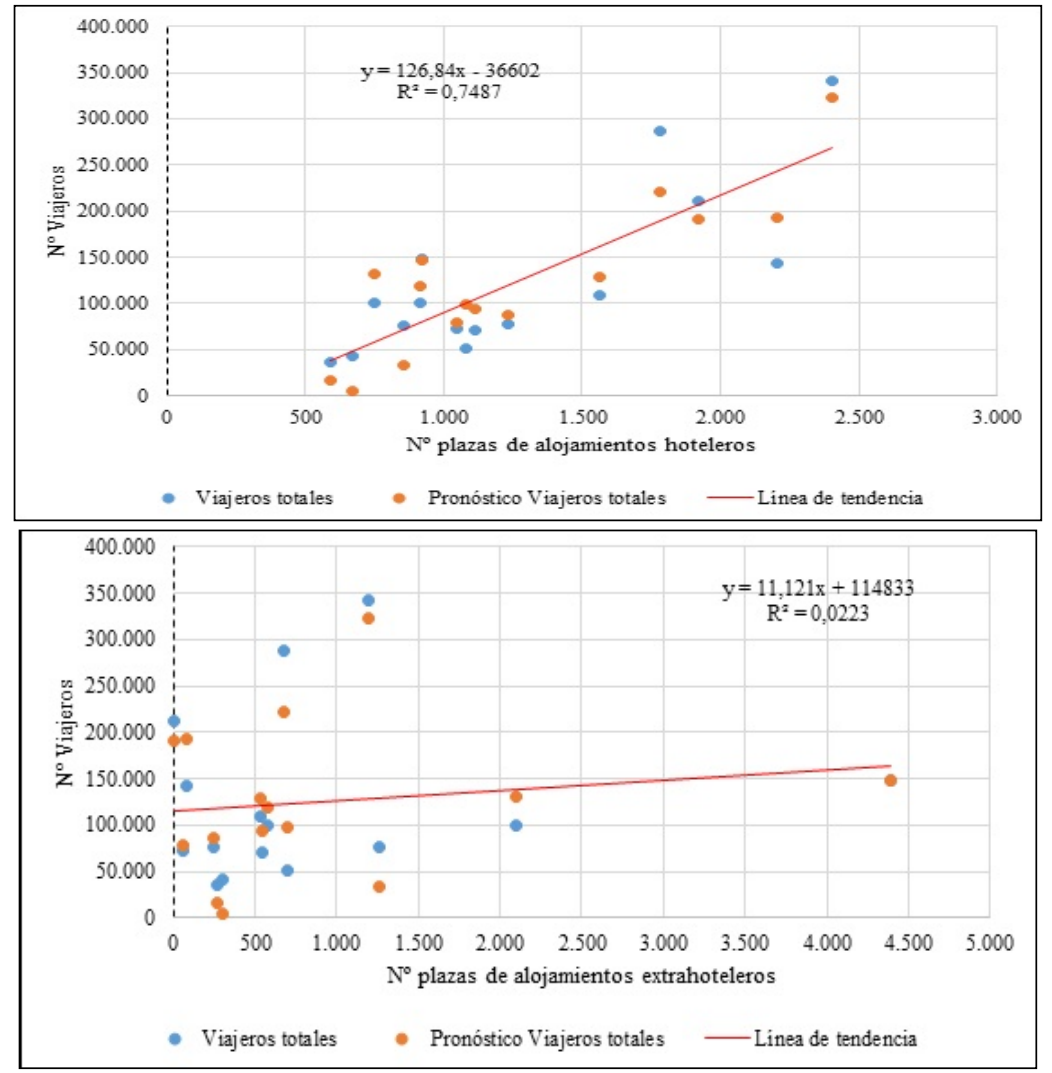




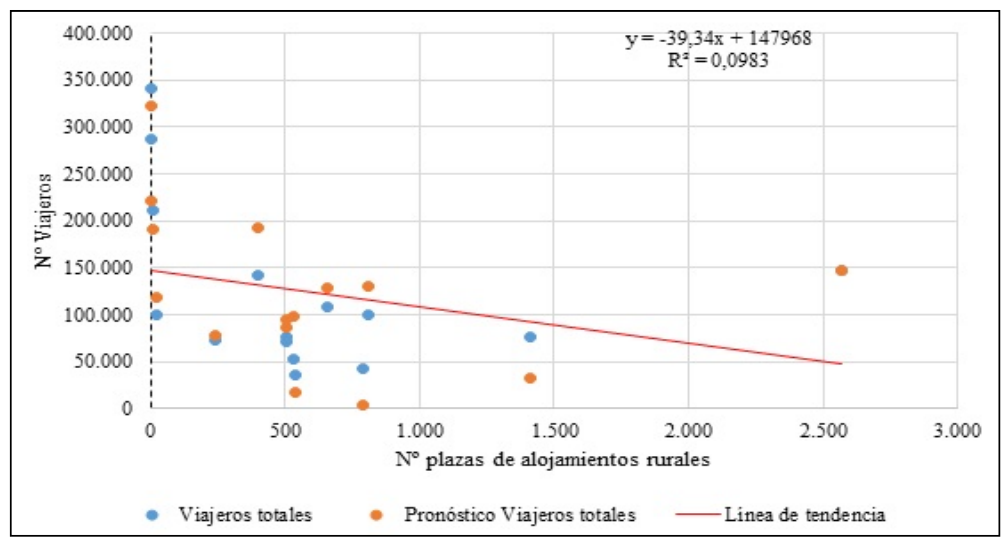

Por último, se calculó el modelo relacionando el número de viajeros con las variables patrimoniales. Así, se obtiene un coeficiente de determinación o $R^{2}$ de 0,808 , por lo que gran cantidad de varianza de la variable dependiente puede ser explicada por las variables explicativas (próximo al valor máximo de 1). Pero, tras estudiar y conocer el valor del estadístico $t$, el valor absoluto en las diferentes variables debe ser 1,943 (para un grado de libertad 6 y un nivel de confianza 95\%), y la variable que está íntimamente relacionada, y con valor negativo $(-3,5)$, es el número total de áreas protegidas (Figura 11). Esto muestra que a aquellos Territorios Turísticos que presentan un elevado número de áreas protegidas se desplaza un menor número de viajeros. Ante esto, se puede confirmar que la presencia de recursos patrimoniales y naturales no está tan correlacionada con el número de viajeros.

Figura 11

\section{CURVA DE REGRESIÓN AJUSTADA DEL TOTAL DE ÁREAS PROTEGIDAS}

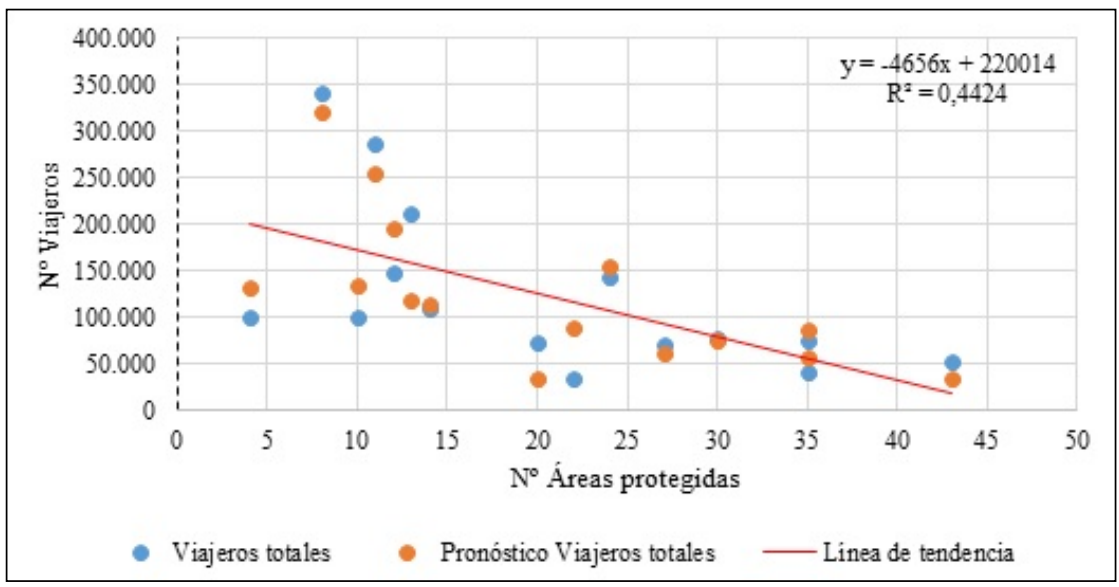




\subsection{Análisis de Componentes Principales}

Por último, se presentan los resultados del Análisis de Componentes Principales (ACP), el cual permite crear un nuevo conjunto de variables ficticias (componentes) mediante el tratamiento de un conjunto de variables observadas. Así, de las más de 100 variables recopiladas y después de las sucesivas depuraciones y el anterior análisis se emplearon, finalmente, 10 variables. Para comprobar que las variables analizadas están correlacionadas entre sí, se calculó el estadístico KMO o medida de adecuación muestral de Kaiser, Meyer y Olkin (Castro y Galindo, 2000; Nieto y Cárdenas, 2017) con un valor de 0,6 , según el cual la correlación existente entre las variables es aceptable.

La explicación de cada una de las variables utilizadas en el ACP se lleva a cabo a través de las comunalidades, un valor que expresa la parte de cada variable, en concreto, su variabilidad, que puede ser expresada por sus factores comunes. En el análisis, cuanto mayor grado de definición posea una variable en todos los componentes principales, más se aproximará a 1. En este estudio, todas las variables comprenden valores de extracción elevados superiores al 0,7, por lo cual, existe una alta explicación de las mismas. Las variables que aportan un mayor peso, todas superiores a 0,8 , son las demográficas y turísticas, como el total de pernoctaciones, los viajeros y el crecimiento de la población. . Por otro lado, la única variable "patrimonial" que se ha introducido en el análisis, el total de áreas protegidas, también presenta una comunalidad significativa, 0,71. Por último, como variable menos explicativa dentro del conjunto, se encuentra el PIB (menos del $0,5)$ por lo que interviene con menor peso en el conjunto, algo que se podido comprobar en el análisis de Regresión Lineal Múltiple.

Tabla 2

COMPONENTE 1

\begin{tabular}{|l|c|}
\hline Población 2018 & 0,619 \\
\hline Crecimiento poblacional (2013-2018) & 0,912 \\
\hline PIB & 0,133 \\
\hline Plazas Alojamientos hoteleros & 0,920 \\
\hline Plazas Alojamientos rurales & $-0,512$ \\
\hline Plazas Alojamientos extrahoteleros & $-0,164$ \\
\hline Plazas Restauración & 0,771 \\
\hline Pernoctaciones totales & 0,813 \\
\hline Viajeros totales & 0,893 \\
\hline Áreas protegidas & $-0,521$ \\
\hline
\end{tabular}

Por otro lado, se obtienen los componentes principales con su varianza total explicada. En este caso, se extraen los tres primeros componentes, explicando conjuntamente el $84,8 \%$ pero se utilizó en este trabajo el primer componente, el cual presenta el 46,89\% de explicación, considerado como el definitorio de la muestra. En la Tabla 2 se exponen las variables y su explicación y en la Figura 12 su representación en los territorios turísticos. 
Su subestructura positiva está formada, con las significancias más altas, por las plazas de alojamientos hoteleros, el crecimiento de la población 2013-2018, los viajeros totales, las pernoctaciones totales y las plazas de restauración, correlacionadas, también, aunque con menor valor, con el PIB y la población total. Se puede comprobar en la representación cartográfica (Figura 12) cómo la mayor puntuación de estas variables se localizan en los territorios turísticos de las ciudades de Cáceres, Mérida y Badajoz y, en menor medida, en otros más ruralizados como Valle del Jerte-La Vera y Valle del Ambroz-Tierras de Granadilla, es estos dos últimos por el mayor número de viajeros y pernoctaciones.

\section{Figura 12 \\ TERRITORIOS TURÍSTICOS DE EXTREMADURA RESPECTO AL COMPONENTE 1}

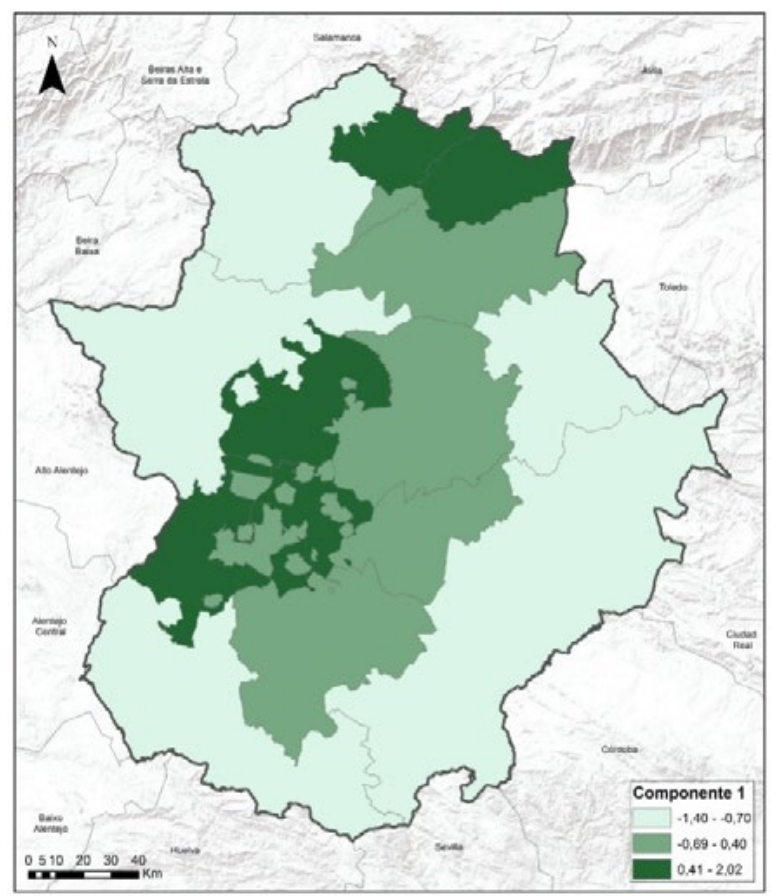

Fuente: Elaboración propia.

De manera opuesta, en la subestructura negativa del Componente 1, aparecen correlacionadas las variables del total de áreas protegidas, plazas de alojamientos rurales y, con un valor inferior, plazas de alojamientos extrahoteleros. Se localizan las variables negativas en los territorios de La Siberia-Campiña Sur, Tajo Internacional-Sierra de San Pedro, Geoparque Villuercas-Ibores-Jara, Sierra de Gata-Las Hurdes-Valle del Alagón y en Alqueva-Sierra Suroeste-Tentudía. Estos territorios aúnan el mayor número de áreas protegidas de la región, en los que su oferta está definida por los alojamientos rurales y 
en los que estas dos variables no son capaces, aún, de atraer un significativo volumen de viajeros y pernoctaciones ni de desarrollar una tendencia demográfica positiva. Los demás territorios presentan valores poco significativos en ambas subestructuras, al tratarse de territorios intermedios y ambiguos con características compartidas de las variables tanto positivas como negativas. Se trata de Plasencia, Tierra de Barros-Zafra, Trujillo-MiajadasMontánchez, Reserva de la Biosfera de Monfragüe y Vegas Altas del Guadiana.

\section{CONCLUSIONES}

Extremadura es una región que cuenta con una riqueza geográfica y biológica excepcional a la que se une su riqueza patrimonial cultural, sus tradiciones y las diferentes fiestas que pueden ofrecer múltiples opciones de turismo relacionados con estos recursos. Así, el objetivo planteado en este trabajo ha sido analizar el sector turístico en los diferentes territorios de Extremadura, en cuanto a la oferta de infraestructuras y recursos y la demanda en cuanto al número de viajeros y pernoctaciones y su relación con variables de contexto de tipo sociodemográfico para determinar que territorios presentan un diseño más óptimo de este sector y su posible correlación con el mantenimiento o crecimiento de la población en los espacios rurales y el PIB.

Estas variables de oferta y demanda se han implementado en un SIG y se han aplicado dos técnicas estadísticas, por un lado, el Análisis de Regresión Lineal Múltiple (OLS), en el que se ha tomado como variable dependiente el número de viajeros que recibe cada uno de los Territorios Turísticos y se ha relacionado con una serie de variables de contexto, y por otro lado, el Análisis de Componentes Principales (ACP), el cual permite observar las relaciones causa-efecto entre variables relativas a tres ámbitos (sociodemográfico, turístico y patrimonial).

Con el OLS se han obtenido variables correlacionadas con el número de viajeros con factor positivo las relativas al crecimiento de la población, las plazas de alojamientos hoteleros, las de alojamientos extrahoteleros y, en menor medida, el tamaño de la población, por lo que se concluye que variables demográficas positivas y la presencia de plazas hoteleras y, en menor grado, de extrahoteleras (apartamentos y campings) ocasiona mayor número de viajeros. Por el contrario, la relación de las plazas de alojamientos rurales (casas rurales fundamentalmente), un elevado número de áreas protegidas y en menor medida el PIB presentan una tendencia negativa. Así, se puede establecer que una mayor oferta de plazas rurales y la presencia de gran cantidad de áreas naturales protegidas con figuras como ZEPAs, Parques Naturales o Geoparques no condiciona a que haya una mayor presencia de viajeros y pernoctaciones. Además, el PIB presenta un sentido negativo, aunque con un valor relativamente bajo, porque existen territorios, en la provincia de Cáceres, muy ruralizados y que no presentan gran dinamismo económico pero que, por localizarse en ellos centrales hidroeléctricas o la nuclear incrementan su PIB municipal.

Con el ACP se ha obtenido un primer componente que presenta un 46,89\% de explicación de la muestra y que se ha determinado como el definitorio de este trabajo. Su subestructura positiva está formada, con las significancias más altas, por las plazas de alojamientos hoteleros, el crecimiento de la población, los viajeros y las pernoctaciones totales y las plazas de restauración, correlacionadas, también, aunque con menor valor, 
con el PIB y la población total. Se pudo comprobar en la representación cartográfica cómo la mayor puntuación de estas variables se localiza en los territorios turísticos de las ciudades de Cáceres, Mérida y Badajoz y, en menor medida, en otros dos territorios más ruralizados del NE de la provincia cacereña que son Valle del Jerte-La Vera y Valle del Ambroz-Tierras de Granadilla. De manera opuesta, en la subestructura negativa de este componente aparecen correlacionadas las variables del total de áreas protegidas, plazas de alojamientos rurales y, con un valor inferior, plazas de alojamientos extrahoteleros. Se localizan las puntuaciones negativas en los territorios situados en áreas periféricas de ambas provincias y de penillanura como La Siberia-La Serena en Badajoz y Tajo Internacional en la provincia cacereña o de sierra en las Villuercas, Hurdes, Gata o San Pedro en Cáceres y Tentudía en Badajoz. Estos territorios aúnan el mayor número de áreas protegidas de la región, en los que su oferta está definida por los alojamientos rurales y en los que estas dos variables no son capaces, aún, de atraer un significativo volumen de viajeros y pernoctaciones ni de desarrollar una tendencia demográfica positiva. Los demás territorios presentan valores poco significativos en ambas subestructuras, al tratarse de territorios intermedios y ambiguos con características compartidas de las variables tanto positivas como negativas. Se trata de Plasencia, Tierra de Barros-Zafra, Trujillo-MiajadasMontánchez, Reserva de la Biosfera de Monfragüe y Vegas Altas del Guadiana.

Con los resultados de estos análisis podemos determinar qué territorios turísticos todavía pueden mejorar datos referentes al sector. Se determina también que el perfil de turistas que visitan la región se desplaza para un turismo patrimonial cultural y gastronómico localizado en las tres principales ciudades y un turismo natural situado fundamentalmente en dos territorios del NE de la provincia de Cáceres (La Vera, Jerte y Ambroz). Por último, reseñar que en el desarrollo del sector turístico está siendo clave la localización espacial de estos territorios respecto al sistema de comunicaciones y la procedencia mayoritaria de los turistas que visitan la región. Así, los que presentan resultados más óptimos son los que se sitúan alrededor de las dos autovías (Ruta de la Plata y A-5) y con unos trayectos hacía la ciudad de Madrid inferiores a las 3 horas.

Debido a lo anterior, se aboga por el estudio de la situación con el fin de crear un marco de actuación común en el ámbito turístico de Extremadura, que fomente el estudio de las externalidades negativas que afectan a la mejora del desarrollo de ciertos territorios, logrando, así, la existencia de un turismo de calidad, sostenible con el medio ambiente y perdurable en el tiempo.

\section{REFERENCIAS BIBLIOGRÁFICAS}

BOSQUE, J. y MORENO, A. (1994): Prácticas de análisis exploratorio y multivariante de datos. Barcelona, Oikos Tau.

BRUNET, P.J., ALMEIDA, F., COLL, M. y MONTESERÍN, O. (2005): «Los planes de excelencia y dinamización turística (PEDT), un instrumento de cooperación a favor del desarrollo turístico», Boletín de la Asociación de Geógrafos Españoles, n ${ }^{\circ}$ 39, pp. 201-226.

CANOVÉS, G. y VILLARINO, M. (2005): «Turismo rural en España: actrices, nuevos usos y nuevas visiones», Cuadernos de Turismo, $\mathrm{n}^{\circ} 15$, pp. 63-76. 
CARRASCO, S. (2005): Aproximación a la estadística desde Ciencias Sociales. Valencia, Universidad de Valencia.

CÁRDENAS, G. y NIETO, A. (2017): «Towards Rural Sustainable Development? Contributions of the EAFRD 2007-2013 in Low Demographic Density Territories: The Case of Extremadura (SW Spain) », Sustainability, vol. 9 (7), 1173.

CASTRO, J.A. y GALINDO, M.P. (2000): Estadística multivariante. Análisis de correlaciones. Salamanca, Amarú Ediciones.

COMITÉ ECONÓMICO Y SOCIAL EUROPEO (2006): La contribución del turismo a la recuperación socioeconómica de las zonas en declive.

CUADRADO, J.R. y LÓPEZ, J.M. (2015): El turismo, motor del crecimiento y de la recuperación de la economía española. Instituto Universitario de Análisis Económico y Social, Documento de Trabajo, Universidad de Alcalá de Henares.

DE UÑA, E. y PÉREZ, M.V. (2011): «Configuraciones de identidad en territorios del turismo. Condiciones generales en Galicia», Cuadernos de Turismo, $\mathrm{n}^{\circ}$ 27, pp. 259272.

DIRECCIÓN GENERAL DE TURISMO DE LA JUNTA DE EXTREMADURA (2017): Plan Turístico de Extremadura 2017-2020.

FISHER, R.A. y YATES, F. (1963): Statistical tables for biological, agricultural and medical research. Edinburgh, Editado por Oliver y Boyd.

GARCÍA, M. y DE LA CALLE, M. (2006): «Turismo en el medio rural: conformación y evolución de un sector productivo en plena transformación. El caso del Valle del Tiétar (Ávila)», Cuadernos de Turismo, no 17, pp. 75-101.

HERNÁNDEZ, M., MOLTÓ, E.A. y RICO, A.M. (2008): «Las actividades turísticoresidenciales en las montañas valencianas», Ería, no 75, pp. 77-97.

IDEEX (2019): Infraestructura de Datos Espaciales de Extremadura. http://www.ideextremadura.com

IEEX (2019): Instituto de Estadística de Extremadura. https://ciudadano.gobex.es/web/ ieex/inicio

Ley $2 / 2011$, de 31 de enero, de desarrollo y modernización del turismo de Extremadura. Boletín Oficial del Estado, no 42, de 18 de febrero de 2011, pp. 18739 a 18790.

NIETO, A. (2014): «Base patrimonial», en Treinta años de economía y sociedad extremeña, 1983-2013. Badajoz, Diputación de Badajoz, pp. 87-106.

NIETO, A. y CÁRDENAS, G. (2017): «25 años de políticas europeas en Extremadura: turismo rural y método Leader», Cuadernos de Turismo, no 39, pp. 389-416.

NIETO, A. y CÁRDENAS, G. (2017): «Análisis del Método Leader (2007-2013) en Extremadura mediante técnicas SIG y Análisis Multivariado», Cuadernos Geográficos, vol. 56 (1), pp. 148-171.

OBIOL, E.M. (2002): «Marcas turísticas y territorio. Un análisis geográfico del turismo valenciano», Cuadernos de Turismo, $\mathrm{n}^{\circ}$ 9, 85-102.

OBSERVATORIO DE TURISMO DE EXTREMADURA (2019). http://observatorio. turismoextremadura.com/.

OBSERVATORIO EXTREMEÑO DE LA CULTURA (2018). https://observaculturaextremadura.es/.

ORGANIZACIÓN MUNDIAL DEL TURISMO (1998): Introducción al turismo. Madrid. 
PÉREZ, J.A. y GARCÍA, Y. (2005): «Turismo rural en Extremadura. El caso del turismo paisano», Revista Española de Estudios Agrosociales y Pesqueros, nº 206, pp. 87-109. PÉREZ, J.A., SÁNCHEZ-ORO, M. y GARCÍA, Y. (2010): «Aproximación a la tipología del" turismo paisano" en las comarcas rurales de procedencia: el caso de Extremadura», en Nuevas perspectivas del turismo para la próxima década: III Jornadas de investigación en turismo, pp. 535-555.

PINEDA, N. B., BOSQUE, J., GÓMEZ, M., y PLATA, W. (2009): «Análisis de cambio del uso del suelo en el Estado de México mediante sistemas de información geográfica y técnicas de regresión multivariantes: Una aproximación a los procesos de deforestación», Investigaciones Geográficas, n ${ }^{\circ}$ 69, pp. 33-52.

RODRÍGUEZ, M. y MORAR, R. (2001): «Análisis de regresión múltiple», en Estadística informática: Casos y ejemplos con el SPSS. Alicante, Universidad Alicante, pp. 109-123.

UNESCO (2019): United Nations Educational, Scientific and Cultural Organization. http://whc.unesco.org/

URIEL, E. (1995): Análisis de datos: series temporales y análisis multivariante. Madrid, Editorial AC.

VÁZQUEZ, C. y MARTÍN, F. (2011): «Problemas de sostenibilidad del turismo rural en España», Anales de Geografía de la Universidad Complutense, vol. 31 (1), pp. 171-194.

VEGAS, J., GARCÍA-CORTÉS, A., LOZANO, G., CARCAVILLA, L., y DÍAZ-MARTÍNEZ, E. (2014): «Valoración de los Lugares de Interés Geológico de Enguídanos (Cuenca) y su aplicación para la geoconservación», en Patrimonio geológico, un recurso para el desarrollo. Madrid, Instituto Geológico y Minero de España, 3 (1), pp. 1.312-1.315. 
